\title{
Eksplorasi Wilayah Mungkajang Kota Palopo Sebagai Sumber Belajaran Geografi
}

\author{
Andi Jumardi ${ }^{a}$, Iin Karmila Putri ${ }^{\text {b }}$ \\ ${ }^{a}$ Universitas Cokroaminoto Palopo \\ Corresponding e-mail: akupendidik44@gmail.com
}

Abstrak: Tujuan penelitian ini untuk mengetahui didaerah mana saja pada wilayah Mungkajang yang dapat dijadikan sebagai sumber belajar alam bagi para pelajar yang mendekatkan keilmuan pada ilmu geografi atau ilmu kebumian. Metode penelitian ini menggunakan pendeskripsian setiap lokasi yang dijadikan sebagai sumber belajar alam. Hasil penilitian ini menunjukkan tiga lokasi pembelajaran dialam membentang diwilayah Mungkajang, setiap lokasi memiliki deskripsi lokasi atau deskripsi tentang keadaan fisik pada lokasi tersebut. Deskripsi yang dilakukan ialah keadaan Morfologi, Geologi dan Hidrologi disetiap lokasi. Ketiga lokasi tersebut adalah Kelurahan Murante, Kelurahan Kambo dan Kelurahan Latuppa. Dijadikannya sebagai sumber belajar alam karena setiap lokasi ini memiliki sifat fisik yang dapat mewakili kawasan wilayah mungkajang. Alam sebagai sumber belajar memiliki manfaat yang lebih banyak baik terhadap pelajar atau siapa yang menjadi pengajar tersebut. Teori yang diterima dapat secara langsung dibuktikan dilapangan. Dan pelajar tidak hanya lagi dibatasi oleh ruang untuk sebuah pemahaman tentang keadaan bumi yang sebenarnya..

Kata Kunci: Eksplorasi, Mungkajang, Sumber, Belajar, Geografi

Abstract: The purpose of this study is to find out which areas in the Mungkajang region can be used as a source of natural learning for students who bring science closer to geography or earth science. This research method uses the description of each location that is used as a natural learning resource. The results of this study indicate three natural learning locations stretching across the Mungkajang region, each location has a location description or a description of the physical state at that location. The description carried out is the state of Morphology, Geology, and Hydrology in each location. The three locations are Murante Village, Kambo Village and Latuppa Village. He made it as a natural learning resource because each of these locations has physical properties that can represent the region of Mungkajang. Nature as a source of learning has more benefits both to students or who becomes the instructor. The accepted theory can be directly proven in the field. And students are no longer limited only by space for an understanding of the true state of the earth.

Keywords: Exploration, Mungkajang, Resources, Learning, Geography 


\section{PENDAHULUAN}

Kecamatan Mungkajang merupakan salah satu kecamatan di Kota Palopo memiliki luas wilayah 53,8 km2, terdiri dari empat kelurahan yaitu Kelurahan Mungkajang, Kelurahan Murante, Kelurahan Latuppa dan Kelurahan Kambo. Status kelurahan di Kecamatan Mungkajang terbagi kedalam dua kategori yakni status perkotaan yaitu Kelurahan Mungkajang, sedangkan tiga kelurahan lainnya yaitu Kelurahan Murante, Latuppa, dan Kambo memiliki status pedesaan. Jarak ibukota kecamatan yang berada di Kelurahan Mungkajang berjarak sekitar $3 \mathrm{~km}$ dari Kota Palopo (1).

Saat ini wilayah Mungkajang dijadikan sebagai wilayah ekowisata. Hal ini disebabkan karena berbagai macam fenomena-fenomena alam yang terjadi di wilayah ini. Wilayah Mungkajang memiliki bentang lahan yang unik karena didominasi oleh topografi pegunungan selain itu terdapat juga berbagai formasi batuan yang ada di wilayah Mungkajang dan terdapat juga pola aliran sungai yang membentang sepanjang wilayah Mungkajang (5). Sesungguhnya kawasan ini juga memiliki potensi ekonomi lain yang tidak kalah penting, yaitu nilai jasa lingkungan (environmental services) seperti sumberdaya air, keanekaragaman hayati, keunikan bentang alam dan obyek wisata alam (5). Wilayah Mungkajang sangat kompleks untuk dijadikan sumber belajar khususnya ilmu geografi karena wilayah ini merupakan suatu cagar alam yang menyajikan objek kejadian kejadian alam, dimana objek alam dapat menjadi suatu sarana pembelajaran geografi yang hampir semua materi geografi dapat tercakupi di wilayah ini.

Dalam memilih sumber belajar yang harus diperhatikan oleh guru/instruktur yaitu sumber belajar harus memiliki kriteria ekonomis, praktis, mudah dan fleksibel sehingga dapat sesuai dengan tujuan dalam mendukung proses dan pencapaian tujuan belajar, yang nantinya akan dapat membangkitkan motivasi dan minat belajar peserta didik dalam belajar. Alam dapat dijadikan sumber belajar karena alam dan lingkungan semesta adalah sumber belajar yang tak terbatas yang menyediakan begitu luas kemungkinankemungkinan yang dapat terjadi (7).

Geografi merupakan istilah yang dikenal sejak lama. Dalam dunia perdagangan, militer, dan politik, istilah itu sering digunakan dan telah dikenal sejak lama. Namun, sebagai "disiplin ilmu dan mata pelajaran" bidang itu masih dianggap kurang populer. Kekurang populeran itu terjadi karena sistem pembelajaran dalam pendidikan persekolahan masih menempatkan bidang ini secara kurang proporsional. Dalam kurikulum sekolah, pada masa itu geografi diberi nama ilmu bumi sehingga obyek yang dikaji terfokus pada fenomena alam, sementara kajian fenomena manusia kurang mendapat perhatian yang seimbang (6).

Masalah lain adalah bahwa pendekatan dalam proses pembelajaran masih terlalu didominasi peran guru (teacher centered). Guru lebih banyak menempatkan peserta didik sebagai objek dan bukan sebagai subjek didik. Pendidikan kita kurang memberikan kesempatan kepada peserta didik dalam berbagai mata pelajaran, untuk mengembangkan kemampuan berpikir holistik (menyeluruh), kreatif, objektif, dan logis. Kegiatan pembelajaran selama ini hanya berlangsung di ruang-ruang kelas dengan memanfaatkan sumber pembelajaran yang monoton, dan belum memanfaatkan kegiatan di luar kelas (outdoor activities), sehingga guru mengalami kesulitan melaksanakan kegiatan pembelajaran yang bervariasi. Akibatnya pembelajaran geografi berlangsung kaku dan formal. Every place is a school, every one is teacher. Artinya bahwa setiap orang adalah guru, guru bisa siapa saja, dimana saja, serta hadir kapan saja, tanpa batas ruang, waktu, kondisi apapun. Dengan demikian siapa saja dapat menjadi guru dan pembelajaran tidak harus berlangsung di dalam kelas, sebab setiap tempat dapat menjadi tempat untuk belajar (7). Konsep Paulo Freire sangat tepat bila dihubungkan dengan metode outdoor activities. Outdoor activities dapat menjadi salah satu alternatif bagi pengayaan sumber pembelajaran.

Pendekatan kontekstual (Contextual Teaching and Learning /CTL) merupakan konsep belajar yang membantu guru mengaitkan antara materi yang diajarkan dengan situasi dunia nyata sehingga mendorong siswa membuat hubungan antara pengetahuan yang dimilikinya dengan penerapannya dalam kehidupan mereka sebagai anggota keluarga dan masyarakat. Dengan konsep itu, hasil pembelajaran diharapkan lebih bermakna bagi siswa. Proses pembelajaran berlangsung alamiah dalam bentuk kegiatan siswa bekerja dan mengalami 


\section{METODE}

a. Jenis penelitian

Penelitian ini bersifat deskriptif kualitatif yang bertujuan untuk mendeskripsikan kelayakan wilayah Mungkajang untuk desain sumber belajar.

b. Desain Penelitian

Adapun desain penelitian yang terdiri atas langkah-langkah dan rancangan penelitian yang ditempuh oleh penelitian ini yaitu :

1) Langkah-langkah penelitian

a) Pra kerja lapangan, yaitu langkah awal dalam pelaksanaan penelitian didalamnya terdiri dari penyiapan data dasar, berupa data sekunder geospasial dan atribut.

b) Tahap kerja lapangan, yaitu penelusuran atau pencarian data primer dengan menggunakan metode hiking. Pada pelaksanaan hiking disertakan dengan pencatatan dan inventarisir data lapangan juga penentuan posisi koordinat hingga pemetaan.

c) Pasca kerja lapangan, yaitu tahap pengelolaan dan analisis data primer yang ditemukan di lapangan kemudian diklasifikasi berdasarkan kebutuhan penyusunan sumber belajar.

2) Rancangan penelitian

Rancangan penelitian merupakan perlakuan terhadap penelitian. Dalam penelitian ini yang dilakukan berupa pengumpulan dan interpretasi data yang ditemukan dilapangan maupun juga data sekunder yang kemudian dianalisis secara logis dan sistematis untuk dijadikan sebagai desain model pembelajaran (4)..

\section{HASIL DAN PEMBAHASAN}

\subsection{Deskripsi Lokasi Penelitain}

Kecamatan Mungkajang merupakan salah satu kecamatan yang ada di Kota Palopo yang memiliki luas wilayah $53,8 \mathrm{~km} 2$, terdiri dari empat kelurahan yaitu Kelurahan Mungkajang, Kelurahan Murante, Kelurahan Latuppa dan Kelurahan Kambo. Status kelurahan di Kecamatan Mungkajang terbagi kedalam dua kategori yakni status perkotaan yaitu Kelurahan Mungkajang, sedangkan tiga kelurahan lainnya yaitu Kelurahan Murante, Latuppa, dan Kambo memiliki status pedesaan. Jarak ibu kota kecamatan yang berada di Kelurahan Mungkajang berjarak sekitar $3 \mathrm{~km}$ dari Kota Palopo.

Keadaan geogafis kecamatan ini didominasi oleh topografi pegunungan. Secara administratif,
Kecamatan Mungkajang berbatasan dengan Kecamatan Wara Barat di sebelah utara, Kecamatan Sendana di sebelah selatan, Kecamatan Wara di sebelah timur, dan Kabupaten Luwu di

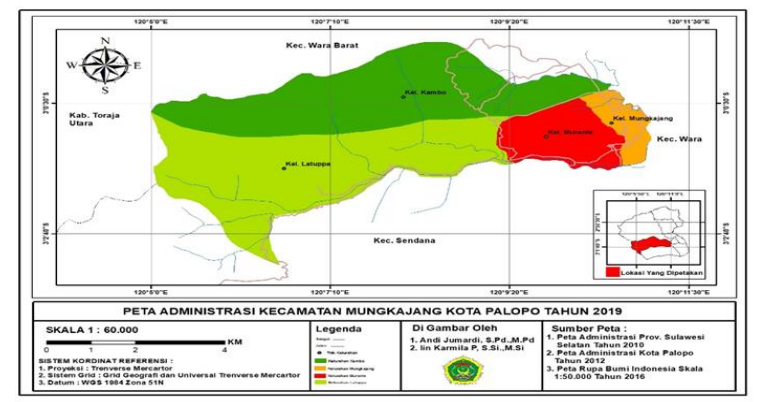

sebelah barat. Bisa dilihat pada gambar 1 peta admnistratif Kecamatan Mungkajang

Gambar 1. Peta administrasi Kecamatan Mungkajang

\subsection{Lokasi Sumber Belajar}

Dalam penelitian ini lokasi yang dapat dijadikan sebagai sarana dan media pembelajaran geografi di Kecamatan Mungkajang terdapat 3 (Tiga) lokasi yang terbagi dari 3 kelurahan adapun yang menjadi lokasi pembelajaran geografi yaitu Kelurahan Murante, Kelurahan Kambo dan Kelurahan Latuppa. Dipilihnya ke 3 (Tiga) lokasi tersebut karena dari lokasi-lokasi ini terdapat berbagai fenomena-fenomena geografis seperti kondisi geologi, kondisi hidrologi, kondisi morfologi dan kondisi biogeografi selain itu lebih mendekatkan pada kajian fisik lokasi yang dapat mewakili pembelajaran geografis. Selain itu aksesbilitas kelokasi pembelajaran cukup bagus dan cukup memadai. Bisa dilihat pada gambar dibawah ini peta citra lokasi pembelajaran Kecamatan Mungkajang.

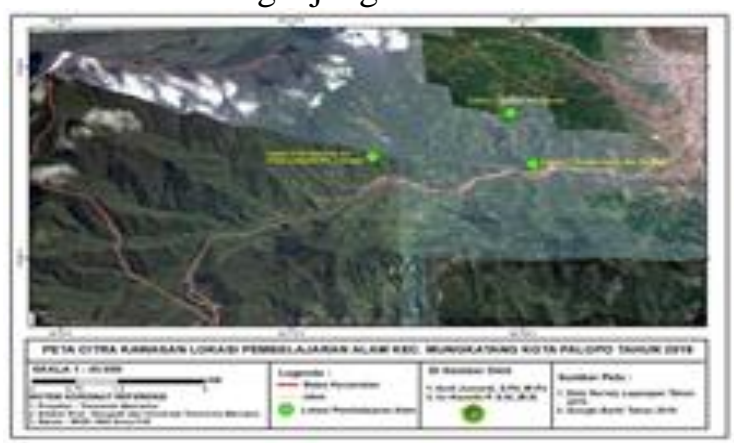

Gambar 2. Peta Lokasi Pembelajaran Kecamatan Mungkajang 


\subsubsection{Lokasi Pertama (Kambo)}

Lokasi pertama yang dapat dijadikan sebagai sumber belajar geografi adalah Kambo. Secara letak astronomis kambo berada pada koordinat 300'21,6'LS, 12008'50,1'BT dengan elevasi 408 Mdpl. Daerah ini merupakan salah satu tempat wisata dimana wilayah kambo terdapat berbagai objek wisata salah satunya Highland Kambo dan Puncak Kambo dari lokasi ini Kota Palopo dan sekitarnya dapat terlihat. Untuk menuju lokasi ini kita harus melewati jalan alternatif Kecamatan Wara Barat dengan kondisi yang berbukit dan pegunungan. Dijadikannya sebagai sumber belajar karena dikawasan ini banyak terdapat objek-objek geografis yang mungkin sangat bermanfaat untuk pendidikan yang berlatar belakang ilmu kebumian.

Kondisi Morfologi

Kemiringan Lereng merupakan bentuk dari variasi perubahan permukaan bumi secara global, regional atau di khususkan dalam bentuk suatu wilayah tertentu variabel yang di gunakan dalam pengidentifikasian kemiringan lereng adalah sudut kemiringan lereng, titik ketinggian di atas muka laut dan bentang alam berupa bentukan akibat gaya satuan geomorfologi yang bekerja. Secara definisi bahasanya lereng merupakan bagian dari bentang alam yang memiliki sudut miring dan beda ketinggian pada tempat tertentu sehingga dapat di tarik suatu kesimpulan bahwa dari sudut (kemiringan) lereng merupakan suatu variabel beda tinggi antara dua tempat, yang di bandingkan dengan daerah yang relatif lebih rata atau datar. Bentukan lahan kawasan kambo adalah wilayah perbukitan-pengunungan. Sebelah utara-barat sangat nampak jelas pengunungan panjang membentang dikawasan kambo ini. Kawasan kambo dilihat dari segi kemiringan lerengnya berada pada 21 - 55\% dengan beda tinggi 200 hingga $500 \mathrm{~m}$, sehingga wilayah ini masuk kategori perbukitan-pengunungan. Sehingga wilayah kawasan kambo masuk ketegori rawan dengan longsor.

Gambar 3. Kondisi Morfologi Kambo

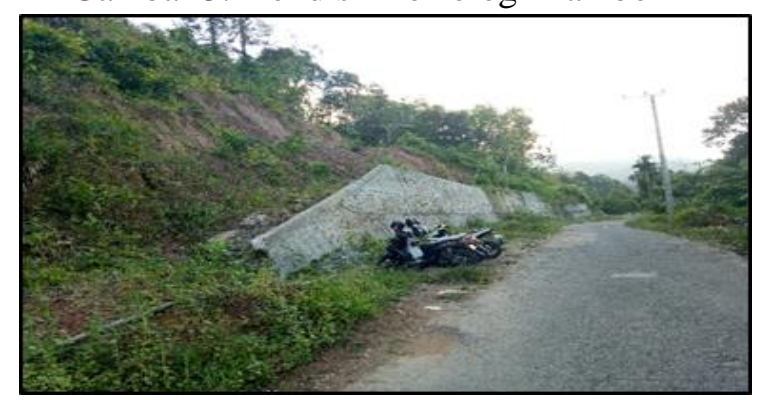

\subsubsection{Lokasi Kedua (Permadian Alam Sungai Jodoh)}

Lokasi kedua yang dapat dijadikan sebagai sumber belajar geografis adalah permandian alam sungai jodoh. Secara letak geografis permandian alam sungai jodoh berada pada Kelurahan Murante sebelah utara berbatasan dengan Kelurahan Kambo, sebelah selatan berbatasan Kecamatan Sendana, sebelah barat berbatasan dengan Kelurahan Latuppa dan sebelah timur berbatasan dengan Kelurahan Mungkajang. Secara letak astronomis sungai jodoh berada pada titik koordinat 030 01'27,48' LS dan 1200 9' 28, 5'BT dan berada pada ketinggian 111 Mdpl. Jarak dari jalan poros ke lokasi sungai jodoh $\pm 20 \mathrm{M}$. Lokasi ini dijadikan sebagai tempat wisata yang biasanya masyarakat menyebutnya sungai jodoh. Pada saat kita memasuki kawasan ini kita dapat melihat atau mempelajari beberapa objek kajian Geografi fisik yang berada pada kawasan objek wisata sungai jodoh.

Kondisi Geologi

Jenis batuan yang terdapat di lokasi kedua adalah batuan lava intermediate jenis batuan seperti ini masuk ketegori jenis batuan beku. Sepanjang aliran sungai terdapat endapan sungai, aliran lava dan batuan granit. Proses terbentuknya batuan beku diakibatkan karena adanya magma yang mengeras atau mengalami proses pembekuan. Magma ini berasal dari batuan setengah cair ataupun oleh batuan yang sudah ada sebelumnya baik yang berada di mantel maupun dikerak bumi. Geologi daerah penelitan terdiri dari beberapa jenis batuan yaitu endapan sungai, aliran lava dan granit.

Endapan Sungai

Batuan ini merupakan batuan termuda dalam lokasi penelitian. Endapan ini terada di sepanjang sungai Latuppa. Endapan ini berasal dari hasil pelapukan batuan yang berada di bagian hulu sungai Latuppa yang tertransportasi oleh media air. Material yang tertransportasi ini kemudian terendapkan di sepanjang sungai Latuppa yang membentuk endapan sungai. Kenampakan lapangan memperlihatkan endapan ini memiliki ukuran butir yang halus - kasar. Bisa dilihat pada gambar di bawah ini.

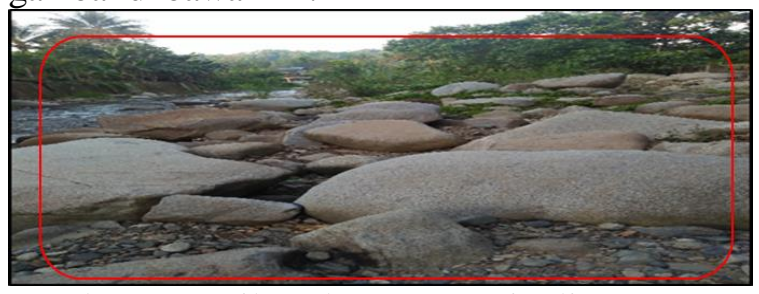

Gambar 4. Hasil Endapan Sungai Aliran Lava 
Batuan ini terbentuk dari aliran lava yang mengeras. Kenampangan lapangan berupa tubuh batuan warna hitam. Singkapan batuan ini dapat diamati di beberapa tempat di sungai Latuppa salah satunya di permandian alam Sungai Jodoh. Bisa dilihat pada gambar dibawah ini.

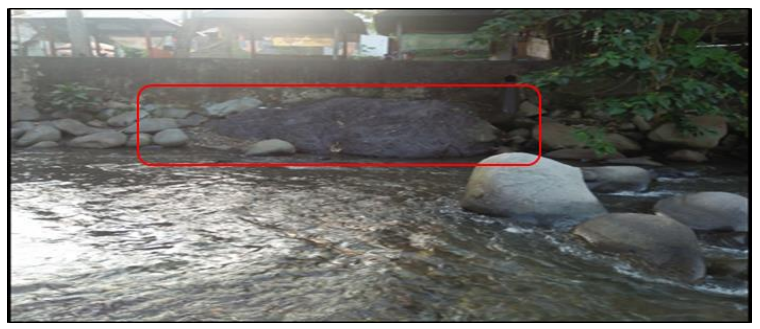

Gambar 5. Aliran Lava (Batuan Beku)

\section{Granit}

Batuan ini merupakan batuan intrusi yang menerobos batuan di atasnya yang berumur lebih tua. Singkapan batuan ini terdapat di beberapa tempat aliran sungai permandian sungai jodoh berbentuk bongkahan dengan warna abu-abu. Di beberapa tempat pada batuan granit terdapat uraturat kuarsa. Bisa dilihat pada gambar dibawah ini.

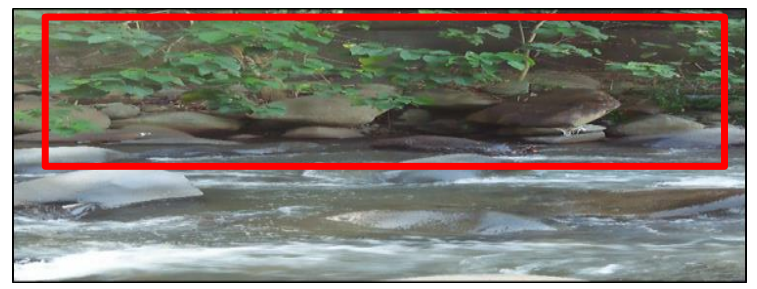

Gambar 6. Batuan Granit

\subsection{Lokasi Ketiga (Permandian Alam Latuppa}

Pembelajaran alam dalam ilmu kebumian yakni adanya fenomena alam yang dapat mewakilkan kenampakan proses yang terjadi didaerah latuppa.

Kondisi Hidrologi

Sistem aliran air sungai pada daerah ini terdapat jenis aliran terjun. Proses terjadinya pola aliran air terjun diseababkan kerena adanya erosi (pengikisan) yang diakibatkan oleh air terhadap lapisan soft rock di badan sungai. Pembentukan air terjun berlangsung secara terus-menerus oleh air dan terjadi dalam jangka waktu yang lama. Aliran terjun pada kawasan ini memiliki ketinggian kurang lebih 4 meter dan memiliki 2 cabang aliran air terjun. Lokasi ini pun dijadikan lokasi wisata permandian air terjun oleh para wisatawan. Sungai yang berada pada kawasan permandian latuppa ini berada atau tergolong pada daerah aliran sungai (DAS) Latuppa. Selain di permandian air terjun latuppa terdapat juga air terjun di dusun siguntu dengan model pola aliran airnya 1 cabang.
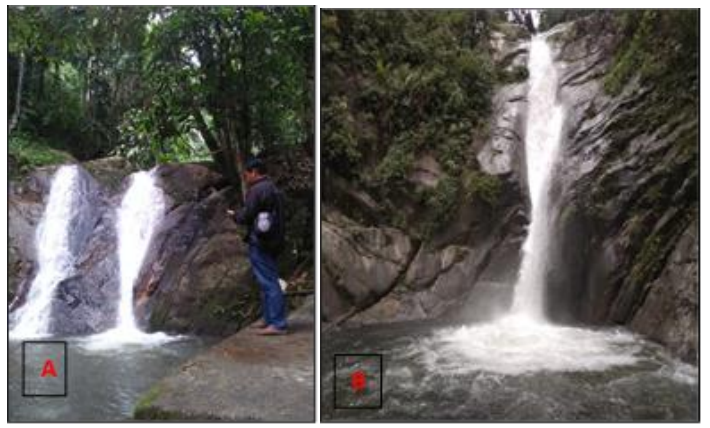

Gambar 7. a. Air terjung yang memiliki 2 cabang aliran air terjun, b. Air terjun yang memiliki 1 cabang aliran air terjun

\section{KESIMPULAN}

Berdasarkan hasil penilitian dan pembahasan yang telah dilakukan pada penilitian ini, dapat ditarik kesimpulan sebagai berikut.

Berlandaskan dari paradigma geografi atau pendekatan geospasial pada sebuah kajian pembelajaran geografi, menekankan pada pendekatan keruangan, kelingkungan dan kewilayahan. Bahwa pembelajaran geografi tidak hanya sebuah dongeng atau menceritakan suatu wilayah keadaan bumi tanpa melihat langsung keadaan atau objek dari suatu kajian terhadap ilmu kebumian, namun hal yang paling penting adalah mendatangi langsung apa saja fenomenafenomena yang ada dialam, karena roh dari geografi adalah lapangan bukan lagi terfokus dalam ruangan saja.

Menjadikan hutan mungkajang dan sekitarnya sebagai sumber belajar alam geografi adalah langkah awal dari perubahan paradigma seorang pelajar yang mendekatkan pada ilmu kebumian. Mendatangi langsung lokasi tersebut adalah jawaban yang sangat pantas untuk sebuah permasalahan yang ada didalam ruang belajar kita.

Adanya tiga lokasi sumber belajar alam dalam penelitian ini juga akan mewakili dari beberapa lokasi yang sebenarnya dapat juga menjadi sumber belajar hutan mungkajang dan sekitarnya

Media pembelajaran dalam berbentuk sebuah video atau rekaman dari ketiga lokasi tersebut juga akan membantu bagi pelajar yang tidak dapat 
datang kelokasi secara langsung dan melihat kondisi atau keadaan geografi pada lokasi tersebut. Agar para pelajar tidak lagi berkhayal pada kenampakan-kenampakan yang berada wilayah mungkajang dan sekitarnya.

\section{DAFTAR PUSTAKA}

Aryadi, 2017. Kajian Zona Arahan Penggunaan Lahan Daerah Mungkajang, Kota Palopo. Lomba Karya Tulis Ilmiah 50 UNCP

A Nurfalaq, A Jumardi. 2019. Identifikasi Batuan Bawah Permukaan Daerah Longsor Kelurahan Kambo Kota Palopo Menggunakan Metode Geolistrik Konfigurasi Dipole-Dipole. Jurnal Geocelebes 3 (2) 66-74

Bintarto \& Surastopo. 2002. Metode Analisa Geografi. Jakarta: LP3ES

Budi Utomo Putra. A, 2011. Bentang Lahan Karst Bantimurung Kabupaten Maros Sebagai Media Sumber Belajar. Fakultas Matematika dan Ilmu Pengetahuan Alam Universitas Negeri Makassar. Skripsi ini tidak dipublikasikan.

Feri Padli Dkk. 2017. Identifikasi Kemiringan Lereng Di Kawasan Pemukiman Kecamatan Mungkajang Berbasis Geographic Information Sistem. Prosiding Seminar Nasional. Vol 1. No (1)

Prasad, Abd. Hallaf H. 2013. Mengamati Fenomena Geografi. Digna

Purwanto. 2009. Memanfaatkan Alam sebagai sumber belajar 'Universitas Negeri Jakarta'.

Purwanto. 2010. Model dan Pengembangan Desain Pembelajaran. Universitas Negeri Jakarta

Indarto. 2013. Sistem Informasi Geografis. Graha Ilmu. Yogyakarta 